\title{
Price Equalization Does Not Imply Free Trade
}

\author{
Piyusha Mutreja, B. Ravikumar, Raymond G. Riezman, and Michael J. Sposi
}

In this article, the authors demonstrate the possibility of price equalization in a two-country world with barriers to international trade. For price equalization to occur when the countries are asymmetric, the country with higher productivity must also be the one with the lower trade barrier. A corollary of the authors' result is that small departures from purchasing power parity do not necessarily imply that world trade is mostly integrated. (JEL F11, F13, F14)

Federal Reserve Bank of St. Louis Review, Fourth Quarter 2015, 97(4), pp. 323-39.

$\mathbf{T}$ he literature on purchasing power parity (PPP) relates free trade to price equalization. Based on a no-arbitrage argument, PPP suggests that a price index constructed with multiple goods in each country should be the same across countries when there are no barriers to international trade. Our focus is on the reverse direction: Does price index equalization across countries necessarily imply that there is free trade?

Our answer is negative: Price equalization does not imply free trade. We illustrate our result in the two-country model of Dornbusch, Fischer, and Samuelson (1977). We show that many equilibria exist with price index equalization, even if there is no free trade. Put differently, there exist many trade barrier combinations for which the price indexes are equal. Hence, price equalization by itself does not guarantee zero trade barriers; information on trade flows is crucial to determine whether there are no barriers to trade.

A corollary of our result is that departures from price equalization are not sufficient to pin down departures from free trade-that is, small deviations from PPP do not necessarily imply that world trade is mostly integrated.

In our model, each country is endowed with immobile labor that is the only factor of production. There is a continuum of tradable intermediate goods, all of which are used to produce a composite intermediate good. The technology for producing each intermediate

Piyusha Mutreja is an assistant professor at Syracuse University. B. Ravikumar is deputy director of research at the Federal Reserve Bank of St. Louis. Raymond G. Riezman is the C. Woody Thompson Research Professor of Economics at the Tippie College of Business, University of lowa. Michael J. Sposi is a research economist at the Federal Reserve Bank of Dallas. The authors thank YiLi Chien and Fernando Martin for their comments and Valerie Grossman and Lin Shao for research assistance.

(c) 2015, Federal Reserve Bank of St. Louis. The views expressed in this article are those of the author(s) and do not necessarily reflect the views of the Federal Reserve System, the Board of Governors, or the regional Federal Reserve Banks. Articles may be reprinted, reproduced, published, distributed, displayed, and transmitted in their entirety if copyright notice, author name(s), and full citation are included. Abstracts, synopses, and other derivative works may be made only with prior written permission of the Federal Reserve Bank of St. Louis. 


\section{Figure 1}

Price of Producer Durables (2005 international \$)

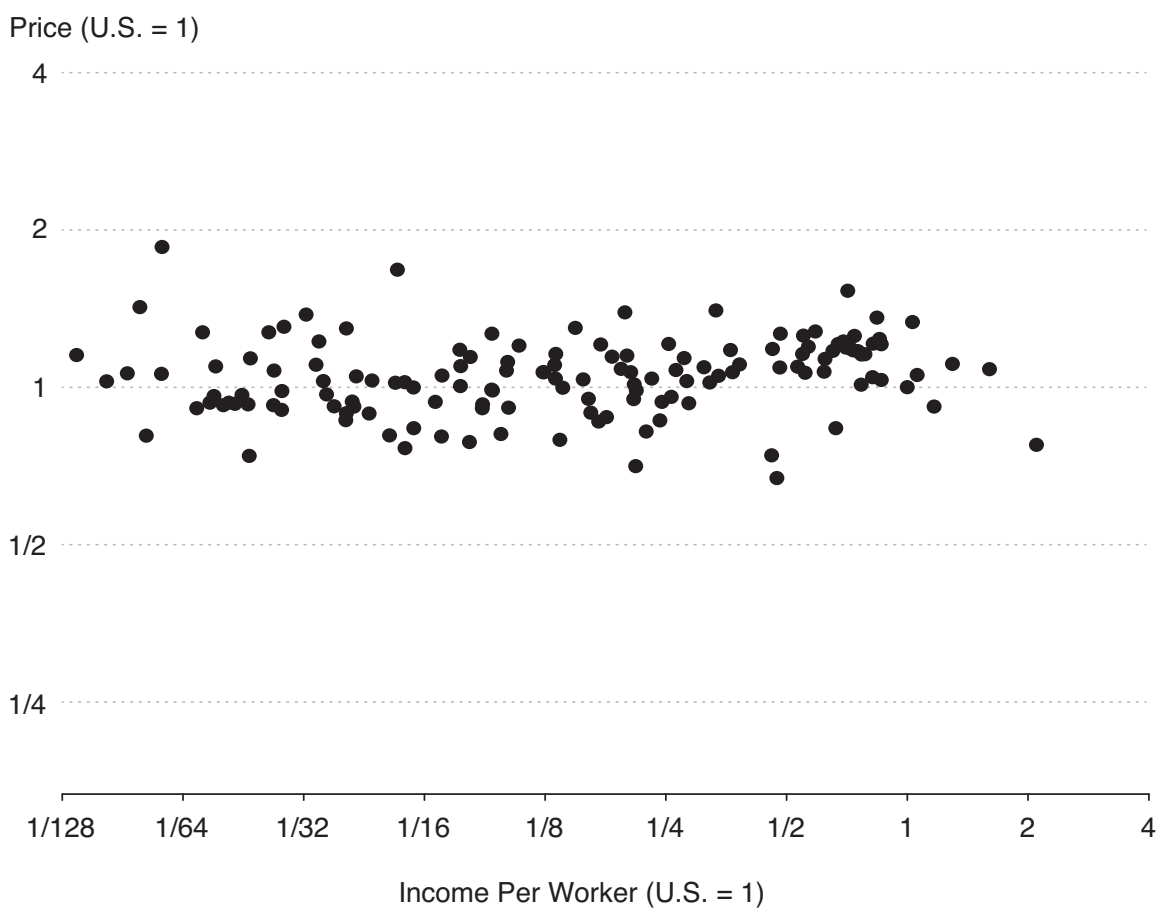

SOURCE: 2005 Benchmark study of the Penn World Table. The sample size is 143.

good differs across the two countries. Trade between the two countries is subject to export barriers in the form of iceberg costs.

The presence of trade barriers implies that the two countries are not completely specialized in production - that is, some intermediate goods in the continuum are not traded but are produced by both countries. The aggregate price (over the continuum of intermediate goods) is a composite of both the prices of intermediate goods that are traded and the prices of intermediate goods that are not traded. For symmetric countries, it is easy to show that the aggregate price is the same in both countries. We also show that the trade flow between the two countries depends on the trade barriers: Large barriers imply a small trade volume, while small barriers imply a large trade volume. Thus, information on trade flows is necessary to infer the magnitude of the trade barriers.

For asymmetric countries, we show numerically that there exist trade barriers such that the aggregate price is the same in both countries. The price equalization in this case depends on a negative relationship between barriers and technology: The country with higher productivity must have a lower export barrier. As in the symmetric case, we show that each trade 
barrier combination implies a different volume of trade. Hence, to infer the presence or absence of trade barriers one needs to know the cross-country trade flows.

Is our result empirically relevant? After all, there is a large literature documenting deviations from PPP (see Taylor and Taylor, 2004, for a summary). There is also a body of work on a stark violation of PPP - the border puzzle (see McCallum, 1995, and Anderson and van Wincoop, 2003). One might be tempted to conclude from the literature that since price equalization is not observed in practice, our theoretical result-price equalization does not imply free trade-is empirically irrelevant. Producer durables trade, however, offers a contrast. Using data from the 2005 Penn World Table, Figure 1 illustrates that the aggregate price of producer durables is roughly equal across countries.

The slope of the best-fitting line for the scatterplot in Figure 1 is an estimate of the (crosscountry) income elasticity of the price of producer durables; the estimate for 2005 in our sample of 143 countries is 0.02 . Hsieh and Klenow (2007) illustrate similar price equalization using 1996 data (see Figure 4, p. 576). The elasticity for 1996 (a sample of 113 countries) is 0.01. Going as far back as 1975, with a sample of only 33 countries in the Penn World Table, the elasticity is 0.02 .

Does the observed price equalization documented above imply that there is free trade in producer durables? Our answer is no. In a model calibrated to deliver the observed trade flows, Mutreja et al. (2014) obtain the price equalization observed in Figure 1 and show that there are substantial barriers to producer durables trade. If the answer had been yes, one could assume that there are no barriers to trade in producer durables, as in Armenter and Lahiri (2012). However, as Mutreja et al. (2014) show, the assumption of free trade in producer durables implies a volume of trade in producer durables that is inconsistent with the observed volume. Alternatively, one could conclude, as Hsieh and Klenow (2007) do, that barriers to trade in producer durables are not systematically related to the level of economic development since the price of producer durables is roughly the same across countries. Again, Mutreja et al. (2014) estimate that productivity is negatively correlated with trade barriers in a model that is consistent with both observed price equalization and observed trade in producer durables.

The rest of the article is organized as follows. The next section describes the two-country model. In a separate section, we demonstrate that it is possible to have price equalization in the presence of barriers to trade.

\section{A TWO-COUNTRY MODEL}

We use the framework of Dornbusch, Fischer, and Samuelson (1977; henceforth DFS). There are two countries, indexed by $i=1,2$. Country $i$ is endowed with labor $L_{i}$, the only factor of production. Labor is not mobile across countries. (Some of the results that follow are well known; they are illustrated here purely for completeness.)

\section{Production}

In each country there is a continuum of tradable intermediate goods; the goods are indexed by $x \in[0,1]$. The technology in country $i$ for producing intermediate good $x$ is as 
follows: It takes $a_{i}(x)$ units of labor to produce 1 unit of good $x$. All intermediate goods are used to produce a composite intermediate good using the technology

$$
Q_{i}=\left[\int_{0}^{1} q_{i}(x)^{1-1 / \eta} d x\right]^{\frac{\eta}{\eta-1}},
$$

where $\eta$ is the elasticity of substitution between any two individual intermediate goods and $q_{i}(x)$ is the quantity of good $x$ used by country $i$.

The final good production technology is linear in the composite intermediate good:

$$
Y_{i}=Q_{i}
$$

The final good is consumed by representative households in the two countries. Both representative households have the same preferences.

Trade barriers take the form of iceberg costs. Let $\tau_{i} \geq 1$ be the trade barrier for exporting a unit from country $i$. That is, for 1 unit to arrive in country 1 , country 2 must export $\tau_{2}$ units. There is no cost for a country to export 1 unit to itself.

All markets are competitive. Labor is paid the value of its marginal product, which is denoted by $w_{i}$. The marginal cost of producing 1 unit of $\operatorname{good} x$ in country $i$ is $w_{i} a_{i}(x)$. So for country 2 to supply 1 unit of good $x$ to country 1 , the cost is $w_{2} a_{2}(x) \tau_{2}$.

\section{Specialization and Trade}

Let $p_{i j}(x)$ be the price, in country $i$, of $\operatorname{good} x$, when the good was produced in country $j$. Each country purchases each good from the country that can deliver it at the lowest price. Hence, the price in country $i$ of any good $x$ is simply $p_{i}(x)=\min \left[p_{i 1}(x), p_{i 2}(x)\right]$. At this point, it is useful to recall the implications for specialization in the DFS model. Define

$$
A(x)=\frac{a_{2}(x)}{a_{1}(x)},
$$

and order the intermediate goods so that $A(x)$ is decreasing in $x$; that is, the goods are ordered in terms of declining comparative advantage for country 1 . In the interval $[0,1]$, country 1 is more productive than country 2 in goods close to 0 and less productive in goods close to 1 .

Goods Produced by Country 1. Country 1 will produce any good $x$ so long as

$$
\begin{array}{rlrl}
p_{11}(x) & \leq p_{12}(x) \\
\Leftrightarrow & w_{1} a_{1}(x) & \leq w_{2} a_{2}(x) \tau_{2} \\
\Leftrightarrow & A(x) \tau_{2} & \geq \frac{w_{1}}{w_{2}} .
\end{array}
$$

Solving this equation we obtain a value $\bar{x}_{1}$ such that country 1 produces all goods $x \in\left[0, \bar{x}_{1}\right]$. Figure $2 \mathrm{~A}$ illustrates the choice of $\bar{x}_{1}$ for $\tau_{2}>1$, given the factor prices $w_{1}$ and $w_{2}$. 


\section{Figure 2}

\section{Specialization in Production of Intermediate Goods}

A. Specialization in Country 1

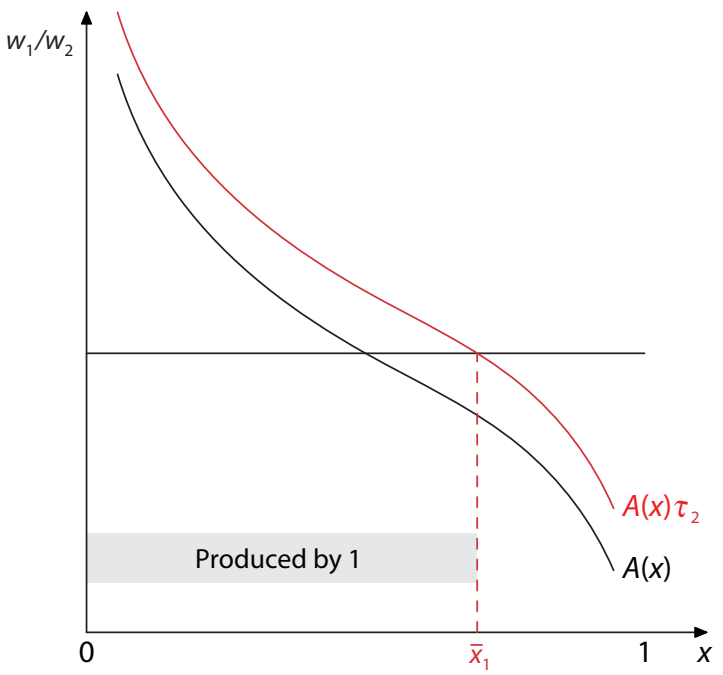

B. Specialization in Country 2

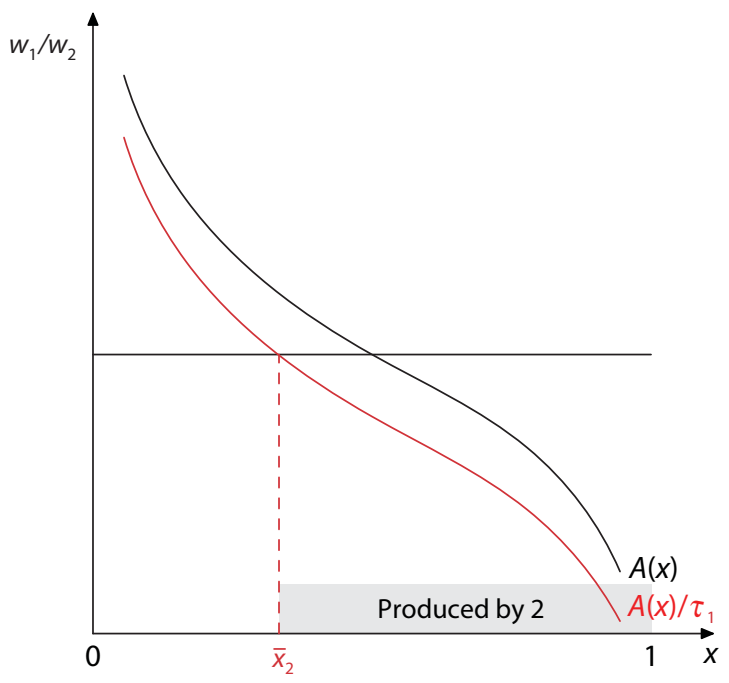

Goods Produced by Country 2. Country 2 will produce any good $x$ so long as

$$
\begin{array}{rlrl}
p_{22}(x) & \leq p_{21}(x) \\
\Leftrightarrow & w_{2} a_{2}(x) & \leq w_{1} a_{1}(x) \tau_{1} \\
\Leftrightarrow & \frac{A(x)}{\tau_{1}} & \leq \frac{w_{1}}{w_{2}} .
\end{array}
$$

By solving this equation we obtain a value $\bar{x}_{2}$ such that country 2 produces all goods $x \in\left[\bar{x}_{2}, 1\right]$; see Figure $2 \mathrm{~B}$ for the case $\tau_{1}>1$.

Traded and Nontraded Goods. Although all intermediate goods along the continuum are potentially tradable, goods in the range $\left[\bar{x}_{2}, \bar{x}_{1}\right]$ are not traded as long as there are trade barriers. Country 2 will import all goods $x \in\left[0, \bar{x}_{2}\right]$, which are precisely the goods they do not produce, while country 1 will import all goods $x \in\left[\bar{x}_{1}, 1\right]$. Put differently, specialization is not complete when there are trade barriers (Figure 3 ). Under free trade, $\tau_{1}=\tau_{2}=1$ and, hence, the two curves in Figure 3 would coincide and $\bar{x}_{1}$ would equal $\bar{x}_{2}$.

Equilibrium. Equilibrium is characterized by a trade balance condition

$$
w_{1} L_{1} \pi_{12}=w_{2} L_{2} \pi_{21}
$$

where $\pi_{i j}$ is the fraction of country $i$ 's spending devoted to goods produced by country $j$. (Recall that the labor endowment in country $i$ is $L_{i}$.) The trade shares $\pi_{12}$ and $\pi_{21}$ are 


\section{Figure 3}

\section{Trade Barriers and Incomplete Specialization}

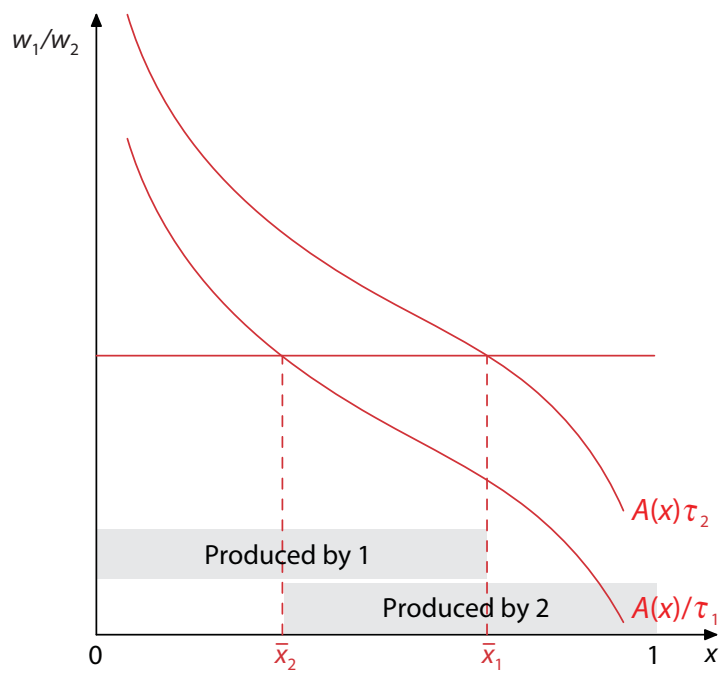

$$
\begin{aligned}
& \pi_{12}=\frac{\int_{\bar{x}_{1}}^{1} p_{1}(x) q_{1}(x) d x}{w_{1} L_{1}}, \\
& \pi_{21}=\frac{\int_{0}^{\bar{x}_{2}} p_{2}(x) q_{2}(x) d x}{w_{2} L_{2}},
\end{aligned}
$$

where $w_{i} L_{i}$ is the total income in country $i$. The home trade shares are $\pi_{11}=1-\pi_{12}$ and $\pi_{22}=1-\pi_{21}$.

The equilibrium price of the composite intermediate good is given by

$$
P_{i}=\left[\int p_{i}(x)^{1-\eta} d x\right]^{\frac{1}{1-\eta}} .
$$

\section{PRICE EQUALIZATION}

In this simple two-country environment, we can write the price index of intermediate goods in each country as the sum of three components based on the range of specialization:

$$
\begin{aligned}
& P_{1}^{1-\eta}=\int_{0}^{\bar{x}_{2}}\left(w_{1} a_{1}(x)\right)^{1-\eta} d x+\int_{\bar{x}_{2}}^{\bar{x}_{1}}\left(w_{1} a_{1}(x)\right)^{1-\eta} d x+\int_{\bar{x}_{1}}^{1}\left(\tau_{2} w_{2} a_{2}(x)\right)^{1-\eta} d x \\
& P_{2}^{1-\eta}=\int_{0}^{\bar{x}_{2}}\left(\tau_{1} w_{1} a_{1}(x)\right)^{1-\eta} d x+\int_{\bar{x}_{2}}^{\bar{x}_{1}}\left(w_{2} a_{2}(x)\right)^{1-\eta} d x+\int_{\bar{x}_{1}}^{1}\left(w_{2} a_{2}(x)\right)^{1-\eta} d x .
\end{aligned}
$$


The price index is an average of the prices over three subintervals: goods produced only by country 1 , goods produced only by country 2 , and goods produced by both countries. Consider first the goods produced only by country 1 . For each of these goods the price in country 2 is equal to the price in country 1 times the barrier of shipping from country 1 to country 2 . A larger barrier of shipping from country 1 to country 2 amplifies the difference in price for each of these goods, which in turn increases the price index in country 2 relative to country 1. Second, consider the goods produced only by country 2 . Using a similar argument, a larger barrier of shipping from country 2 to country 1 decreases the price index in country 2 relative to country 1 . Finally, consider the goods produced by both countries. These are the goods that are not traded. The difference in the price of each of these goods is determined by the difference in the cost of inputs-in this case, the wage. An increase in the trade barrier in either country increases the range of these nontraded goods and results in a larger increase in the price index for the country with a higher cost of production.

\section{Symmetric Countries}

Suppose that the two countries are symmetric in all exogenous variables: $L_{1}=L_{2}, \tau_{1}=\tau_{2}=$ $\tau \geq 1$, and $a_{1}(x)=a_{2}(1-x)$ (i.e., $a_{1}(x)$ is a mirror image of $a_{2}(x)$ ).

Given the symmetry, it is easy to see that the equilibrium specialization is given by $\bar{x}_{1}=$ $1-\bar{x}_{2}$; that is, the range of goods produced in each country would be the same. Then, the trade flow from country 1 to country 2 would be the same as that from country 2 to country 1 :

$\pi_{12}=\pi_{21}$. The trade balance condition (3) then implies $w_{1}=w_{2}$. In Appendix A, we show that $P_{1}=P_{2}$.

Price equalization in the symmetric case depends on the assumption that $\tau_{1}=\tau_{2}=\tau$ and not on whether $\tau=1$ or $\tau>1$. However, the trade flows depend on the barriers. To see this, suppose that there are no trade barriers-that is, $\tau=1$. In this case, the specialization is complete: $\bar{x}_{1}=\bar{x}_{2}=\frac{1}{2}$. Country 1 spends 50 percent of its income on goods from country 2 and vice versa: $\pi_{12}=\pi_{21}=\frac{1}{2}$. Now, suppose $\tau>1$. In the presence of trade barriers, the specialization is incomplete: Goods in the range $\left[\bar{x}_{2}, \bar{x}_{1}\right]$ are produced by both countries but are not traded. This, in turn, affects the trade flows: $\pi_{12}=\pi_{21}<\frac{1}{2}$. Thus, to infer the presence or absence of trade barriers, one needs information on trade flows.

\section{Asymmetric Countries}

To derive the price equalization result for two asymmetric countries, it is useful to have more structure on each country's technology for producing intermediate goods. For symmetric countries, we assumed that the average productivity was the same in both countries and that productivity in country 2 was the mirror image of that in country $1: a_{1}(x)=a_{2}(1-x)$. With the same trade barriers in the two countries, the equilibrium factor price ratio, $w_{1} / w_{2}$, was equal to 1 . We used the equal factor prices to demonstrate that the price index of intermediate goods is the same in both countries. For asymmetric countries, the average productivity is 
different in the two countries, so the equilibrium factor prices need not be the same in the two countries. By imposing more structure on the productivities in the two countries we can determine the equilibrium factor price ratio and, hence, the prices of intermediate goods.

We assume that the comparative advantage function $A(x)=\frac{a_{2}(x)}{a_{1}(x)}=\left(\frac{1-x}{x}\right)^{\theta}\left(\frac{\lambda_{1}}{\lambda_{2}}\right)^{\theta}$, where the average labor productivity in country $i$ is proportional to the parameter $\lambda_{i}$ and the parameter $\theta$ governs the coefficient of variation in productivity. ${ }^{1}$ (The expression for $A(x)$ can be derived by following Eaton and Kortum, 2002. The details are provided in Appendix B.)

Trade Shares. The trade share $\pi_{i j}$ is the fraction of country $i$ 's total spending on intermediate goods that were produced by country $j$. We show in Appendix B that

$$
\pi_{12}=\frac{1}{1+\left(\frac{w_{1}}{w_{2}}\right)^{-1 / \theta} \tau_{2}^{1 / \theta}\left(\frac{\lambda_{1}}{\lambda_{2}}\right)}
$$

$$
\pi_{21}=\frac{1}{1+\left(\frac{w_{2}}{w_{1}}\right)^{-1 / \theta} \tau_{1}^{1 / \theta}\left(\frac{\lambda_{2}}{\lambda_{1}}\right)}
$$

The trade shares in equations (6a) and (6b) are clearly between 0 and 1; that is, each country will specialize in some goods in the continuum. Equations (6a) and (6b) are intuitive. For instance, $\lambda_{1}>\lambda_{2}$ implies lower $\pi_{12}$. If country 1 is more productive than country 2 , then the trade flow from country 2 to country 1 will be less than it would be if country 1 is as productive as country 2. Similarly, a larger export barrier in country 2 implies less trade flow from country 2 to country 1 .

Prices. The trade shares in (6a) and (6b), together with the trade balance condition (3), determine the equilibrium factor price ratio $\frac{w_{1}}{w_{2}}$ :

$$
\frac{w_{1}}{w_{2}}=\left(\frac{L_{2}}{L_{1}}\right)\left(\frac{1+\left(\frac{w_{1}}{w_{2}}\right)^{-1 / \theta} \tau_{2}^{1 / \theta}\left(\frac{\lambda_{1}}{\lambda_{2}}\right)}{1+\left(\frac{w_{1}}{w_{2}}\right)^{1 / \theta} \tau_{1}^{1 / \theta}\left(\frac{\lambda_{2}}{\lambda_{1}}\right)}\right) .
$$

It is clear that there exists a unique relative wage $\frac{w_{1}}{w_{2}}$ that satisfies equation (7).

Using equation (4) and the analytical expression for prices $p_{i}(x)$ (see Appendix B), the relative price between the two countries is given by 


$$
\frac{P_{1}}{P_{2}}=\left[\frac{1+\left(\frac{w_{2}}{w_{1}}\right)^{-1 / \theta} \tau_{2}^{-1 / \theta}\left(\frac{\lambda_{2}}{\lambda_{1}}\right)}{\tau_{1}^{-1 / \theta}+\left(\frac{w_{2}}{w_{1}}\right)^{-1 / \theta}\left(\frac{\lambda_{2}}{\lambda_{1}}\right)}\right]^{-\theta}
$$

If there are no trade barriers, then all goods are traded and PPP holds-that is, if $\tau_{1}=\tau_{2}=1$, then $\bar{x}_{1}=\bar{x}_{2}$ and $P_{1} / P_{2}=1$ regardless of the equilibrium relative wage (see Figure 3 for the determination of $\bar{x}_{1}$ and $\bar{x}_{2}$ ). However, in the presence of trade barriers, the relative price will depend on the relative wage, which is pinned down by equation (7).

Suppose that $\lambda_{1} \neq \lambda_{2}$ and/or $L_{1} \neq L_{2}$. Is it possible to obtain price equalization with trade barriers? As it turns out, the answer is yes. There are many combinations of $\tau_{1}>1$ and $\tau_{2}>1$ that deliver price equalization. However, each combination implies a different volume of trade. For instance, suppose that two pairs of barriers $\left(\tau_{1}, \tau_{2}\right)$ and $\left(\tau_{1}^{\prime}, \tau_{2}^{\prime}\right)$ both generate price equalization. If $\left(\tau_{1}{ }^{\prime}, \tau_{2}{ }^{\prime}\right)>\left(\tau_{1}, \tau_{2}\right)$, then the volume of trade under $\left(\tau_{1}, \tau_{2}\right)$ will be greater than the volume under $\left(\tau_{1}{ }^{\prime}, \tau_{2}{ }^{\prime}\right)$. Put differently, given price equalization, information on trade flows pins down the trade barriers.

Numerical Example. Assume that $\left(\frac{\lambda_{1}}{\lambda_{2}}\right)^{\theta}=4, L_{1}=L_{2}=1$, and $\theta=0.2$. What are the combinations of $\tau_{1}$ and $\tau_{2}$ that deliver price equalization?

The trivial case is free trade: The combination $\tau_{1}=1$ and $\tau_{2}=1$ leads to price equalization. This is easy to see from equation (8). Free trade implies $\bar{x}_{1}=\bar{x}_{2}$ (see Figure 3 for an illustration of specialization by the two countries). Even though $\bar{x}_{1}=\bar{x}_{2}$, free trade does not imply $\bar{x}_{1}=\bar{x}_{2}=\frac{1}{2}$. Country 1 specializes in a larger range of goods: $\bar{x}_{1}>1-\bar{x}_{2}$. The trade flows are given by $\pi_{12}=0.24$ and $\pi_{21}=0.76$. Note, however, that the factor prices $w_{1}$ and $w_{2}$ are not equalized. A close look at equation (7) reveals that if $\lambda_{1}>\lambda_{2}$ and if $\tau_{1}=\tau_{2}=1$, then $\frac{w_{1}}{w_{2}}>1$. Country 1 is, on average, more productive than country 2.

Now consider the case with barriers. One of the combinations that leads to price equalization is $\tau_{1}=1.22$ and $\tau_{2}=1.5$. As noted earlier, since country 1 is more productive than country 2 and its export cost is lower, $\bar{x}_{1}$ must be greater than $\bar{x}_{2}$. Barriers to trade imply incomplete specialization, so there is a range of intermediate goods that are not traded. The trade flows in this case are given by

$$
\left[\begin{array}{ll}
\pi_{11} & \pi_{12} \\
\pi_{21} & \pi_{22}
\end{array}\right]=\left[\begin{array}{ll}
0.91 & 0.09 \\
0.33 & 0.67
\end{array}\right]
$$

For price equalization to occur with asymmetric countries, the export barrier for the lessproductive country must be larger than the export barrier for the more-productive country (Figure $4 \mathrm{~A}$ ). The locus of $\left\{\left(\tau_{2}, \tau_{1}\right) \mid P_{1}=P_{2}\right\}$ lies above the 45-degree line since country 1 is more 
Mutreja, Ravikumar, Riezman, Sposi

\section{Figure 4}

\section{Trade Barriers and Trade Flows Consistent with Price Equalization}

\section{A. Trade Barrier Combinations}

Country 2's Export Barrier: $\tau_{2}$

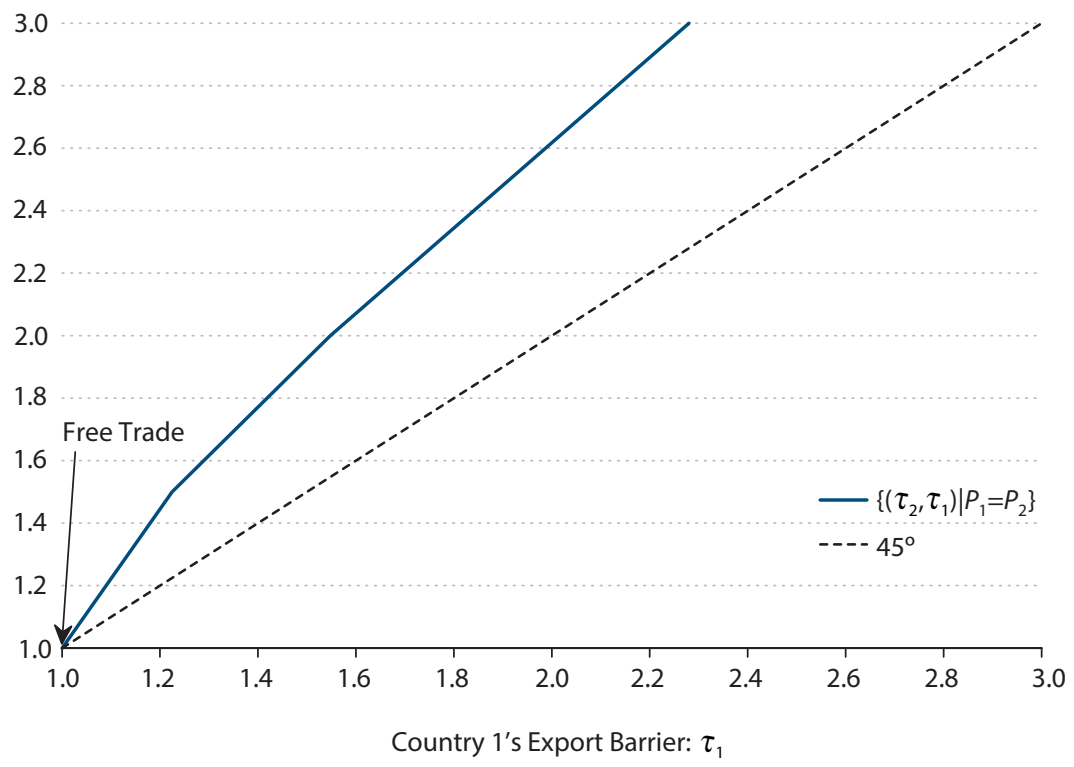

\section{B. Trade Flows}

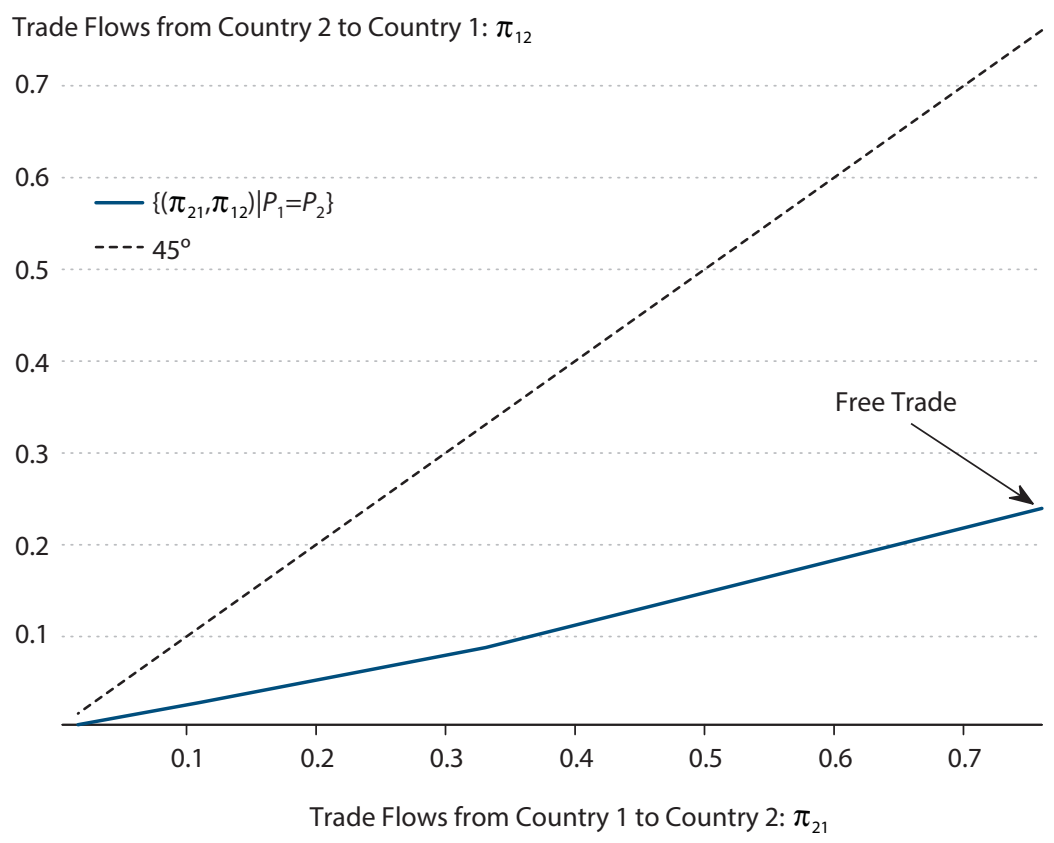


productive. The corresponding trade flows are illustrated in Figure $4 \mathrm{~B}$ by the locus of $\left\{\left(\pi_{21}, \pi_{12}\right) \mid P_{1}=P_{2}\right\}$. Each barrier combination in Figure $4 \mathrm{~A}$ corresponds to a unique trade flow combination in Figure 4B. Larger barriers imply smaller trade flows. All of these combinations deliver price equalization. However, each barrier combination corresponds to a distinct set of trade flows between the two countries.

These trade barrier combinations and productivities are in the empirically plausible range. Mutreja et al. (2014) estimate the average productivity, $\lambda^{\theta}$, in producer durables for a sample of 88 countries in 2005 . In the cross-country distribution of average productivity, the country in the 85 th percentile is 3.8 times as productive as the country in the 15th percentile. The trade-weighted export barrier in the 85 th percentile country is 2.3 , and the corresponding barrier in the 15th percentile country is 4.0 (74 percent higher). In our numerical example, country 1 is four times as productive as country 2 and the barrier in country 2 is 23 percent higher.

Testable Implication. Since price equalization occurs with barriers as well as with free trade, an obvious question at this stage is how would one test whether barriers to trade exist. The relevant empirical case is the one with asymmetric countries. For this case, we showed earlier that it is possible to obtain price equalization even when there are barriers to trade, provided the country with the higher average productivity is also the one with the lower export barrier. In other words, price equalization in our model implies a negative correlation between $\lambda$ and $\tau$. Note that if price equalization implies free trade, then $\tau=1$ for all countries, so the correlation between $\lambda$ and $\tau$ would be zero. Under the weaker inference in Hsieh and Klenow (2007) that the barriers to trade in producer durables are not systematically related to the level of economic development, the correlation between $\lambda$ and $\tau$ would again be zero.

One problem is that the productivity parameter $\lambda$ is not directly observable, so we have to use an observable proxy to test the implication. A convenient proxy for $\lambda$ in our model is real GDP per worker. Real GDP in our model is $\frac{w_{i} L_{i}}{P_{i}}$, so real GDP per worker is

$$
y_{i}=\frac{w_{i}}{P_{i}}
$$

Higher productivity (i.e., higher $\lambda$ ) implies a higher wage rate and, with price equalization, a higher real GDP per worker.

Another problem is that empirically observable trade costs cannot deliver the observed trade flows, so we cannot use the observed trade costs in our test. However, we can use the model-implied relationship between trade flows and trade barriers and construct a testable implication.

In Appendix B, we show that for two asymmetric countries

$$
\frac{\pi_{12}}{\pi_{22}}=\left(\frac{P_{2}}{P_{1}}\right)^{-1 / \theta} \tau_{2}^{-1 / \theta} \text { and }
$$




$$
\frac{\pi_{21}}{\pi_{11}}=\left(\frac{P_{1}}{P_{2}}\right)^{-1 / \theta} \tau_{1}^{-1 / \theta}
$$

Free trade implies $\tau_{1}=\tau_{2}=1$ and $P_{1}=P_{2}$. Thus, both ratios, $\frac{\pi_{12}}{\pi_{22}}$ and $\frac{\pi_{21}}{\pi_{11}}$, must equal 1 . In our numerical example, this implication is confirmed. The matrix of trade flows under free trade is

$$
\left[\begin{array}{ll}
\pi_{11} & \pi_{12} \\
\pi_{21} & \pi_{22}
\end{array}\right]=\left[\begin{array}{ll}
0.76 & 0.24 \\
0.76 & 0.24
\end{array}\right]
$$

With barriers to trade, our numerical example has price equalization along with the implications that $\frac{\pi_{12}}{\pi_{22}}$ is less than $\frac{\pi_{21}}{\pi_{11}}$ and $\tau_{1}$ is less than $\tau_{2}$. That is, country 1 has a higher GDP per worker, higher $\frac{\pi_{21}}{\pi_{11}}$, and lower trade barriers.

In a model with more than two countries, a general version of equations (10a) and (10b) is

$$
\frac{\pi_{1 j}}{\pi_{j j}}=\left(\frac{P_{j}}{P_{1}}\right)^{-1 / \theta} \tau_{j}^{-1 / \theta}
$$

where $j$ denotes any country that exports to country 1 . For producer durables, since the price index is roughly the same across countries, the above equation can be written as

$$
\ln \left(\frac{\pi_{1 j}}{\pi_{j j}}\right)=-\frac{1}{\theta} \ln \tau_{j}
$$

Thus, a testable implication of our model is that the higher the GDP per worker in country $j$ relative to that in country 1 , the higher the ratio $\frac{\pi_{1 j}}{\pi_{j j}}$. Fixing country 1 to be the United States and using the sample of 88 countries from Mutreja et al. (2014) for the year 2005, the correlation between $\ln \left(\frac{\pi_{1 j}}{\pi_{j j}}\right)$ and $\ln \left(\frac{y_{j}}{y_{1}}\right)$ is almost 60 percent. The real GDP per worker in Austria is 86 percent of that in the United States, while the ratio $\frac{\pi_{1 j}}{\pi_{j j}}$ for Austria is 0.21 . The corresponding numbers for Chile are 72 percent and 0.06 and for Laos are 5 percent and 0.002 . Note that under free trade and under the inference that barriers are uncorrelated with economic development, $\frac{\pi_{1 j}}{\pi_{j j}}$ should be uncorrelated with country $j$ 's relative GDP per worker. 


\section{CONCLUSION}

We show theoretically, using a simple two-country model, that the existence of equal price indexes across countries does not imply that there is free trade. Information on trade flows is important in determining the magnitude of the trade barriers. When there are barriers to trade, we demonstrate that price equalization implies that countries with higher average productivity must have lower trade barriers.

\section{APPENDIXES}

\section{A. Price Equalization for Symmetric Countries}

To show that $P_{1}=P_{2}$ for symmetric countries, recall that $\tau_{1}=\tau_{2}=\tau$ and $a_{1}(x)=a_{2}(1-x)$ implies a symmetric equilibrium that is characterized by a "mirror image" specialization, $\bar{x}_{1}=1-\bar{x}_{2}$, and equal wages, $w_{1}=w_{2}=w$. Using equations (5a) and (5b), the price index in each country is given by

$$
\begin{aligned}
& P_{1}^{1-\eta}=\int_{0}^{\bar{x}_{2}}\left(w a_{1}(x)\right)^{1-\eta} d x+\int_{\bar{x}_{2}}^{\bar{x}_{1}}\left(w a_{1}(x)\right)^{1-\eta} d x+\int_{\bar{x}_{1}}^{1}\left(\tau w a_{2}(x)\right)^{1-\eta} d x, \\
& P_{2}^{1-\eta}=\int_{0}^{\bar{x}_{2}}\left(\tau w a_{1}(x)\right)^{1-\eta} d x+\int_{\bar{x}_{2}}^{\bar{x}_{1}}\left(w a_{2}(x)\right)^{1-\eta} d x+\int_{\bar{x}_{1}}^{1}\left(w a_{2}(x)\right)^{1-\eta} d x .
\end{aligned}
$$

Consider the first component of the price index in country 2:

$$
\int_{0}^{\bar{x}_{2}}\left(\tau w a_{1}(x)\right)^{1-\eta} d x=\int_{0}^{1-\bar{x}_{1}}\left(\tau w a_{2}(1-x)\right)^{1-\eta} d x=\int_{\bar{x}_{1}}^{1}\left(\tau w a_{2}(z)\right)^{1-\eta} d z
$$

where the first equality uses the mirror image specialization property and the last equality is due to a change of variables $z=1-x$. Note that the last term in the above equation and the third term in the expression for the price index in country 1 are exactly the same.

Next, consider the second component in the price index in country 2. Using analogous logic,

$$
\int_{\bar{x}_{2}}^{\bar{x}_{1}}\left(w a_{2}(x)\right)^{1-\eta} d x=\int_{1-\bar{x}_{1}}^{1-\bar{x}_{2}}\left(w a_{1}(1-x)\right)^{1-\eta} d x=\int_{\bar{x}_{2}}^{\bar{x}_{1}}\left(w a_{1}(z)\right)^{1-\eta} d z
$$

Note that the last term in the above equation equals the second component in the expression for the price index in country 1.

Finally, consider the third component in the price index in country 2 :

$$
\int_{\bar{x}_{1}}^{1}\left(w a_{2}(x)\right)^{1-\eta} d x=\int_{1-\bar{x}_{2}}^{1}\left(w a_{1}(1-x)\right)^{1-\eta} d x=\int_{0}^{\bar{x}_{2}}\left(w a_{1}(z)\right)^{1-\eta} d z .
$$

The last term in the above equation equals the first component in the expression for the price index in country 1.

Thus, the price indexes are equalized in the symmetric equilibrium: $P_{1}=P_{2}$. 


\section{B. Prices and Trade Flows for Asymmetric Countries}

We follow Eaton and Kortum (2002) and assume that $\frac{1}{a_{1}(x)}$ and $\frac{1}{a_{2}(x)}$ follow independent, country-specific Fréchet distributions. The distributions are characterized by a countryspecific location parameter, $\lambda_{i}$, and common shape parameter, $\theta$. The expected value of $1 / a_{i}(x)$ is proportional to $\lambda_{i}^{\theta}$, so the average labor productivity in country $i$ across the continuum of intermediate goods is proportional to $\lambda_{i}^{\theta}$. Then $A(x) \equiv \frac{a_{2}(x)}{a_{1}(x)}=\left(\frac{1-x}{x}\right)^{\theta}\left(\frac{\lambda_{1}}{\lambda_{2}}\right)^{\theta}$. Furthermore, since $\frac{1}{a_{1}(x)}$ is distributed Fréchet with parameters $\left(\lambda_{i}, \theta\right), a_{i}(x)^{1 / \theta}$ is distributed exponentially with parameter $\lambda_{i}$.

In this section, we show how to derive analytical expressions for price indexes and trade shares for asymmetric countries. Our derivations rely on three properties of the exponential distribution:

Property $1 \quad u \sim \exp (\alpha)$ and $k>0 \Rightarrow k u \sim \exp (\alpha / k)$.

Property $2 \quad u_{1} \sim \exp \left(\alpha_{1}\right)$ and $u_{2} \sim \exp \left(\alpha_{2}\right) \Rightarrow \min \left\{u_{1}, u_{2}\right\} \sim \exp \left(\alpha_{1}+\alpha_{2}\right)$.

Property $3 \quad u_{1} \sim \exp \left(\alpha_{1}\right)$ and $u_{2} \sim \exp \left(\alpha_{2}\right) \Rightarrow \operatorname{Pr}\left(u_{1} \leq u_{2}\right)=\frac{\alpha_{1}}{\alpha_{1}+\alpha_{2}}$.

Price Indexes. We derive the price index, $P_{1}$, for the composite intermediate good in country 1 . The derivation for $P_{2}$ is analogous.

Country 1 purchases each good from the least-cost supplier, so the price of good $x$ is

$$
p_{1}(x)^{1 / \theta}=\min \left[\left(w_{1}\right)^{1 / \theta} a_{1}(x)^{1 / \theta},\left(w_{2} \tau_{2}\right)^{1 / \theta} a_{2}(x)^{1 / \theta}\right] .
$$

Since $a_{j}(x)^{1 / \theta} \sim \exp \left(\lambda_{j}\right)$, it follows from Property 1 that

$$
\begin{gathered}
\left(w_{1}\right)^{1 / \theta} a_{1}(x)^{1 / \theta} \sim \exp \left(\left(w_{1}\right)^{-1 / \theta} \lambda_{1}\right) \text { and } \\
\left(w_{2} \tau_{2}\right)^{1 / \theta} a_{2}(x)^{1 / \theta} \sim \exp \left(\left(w_{2} \tau_{2}\right)^{-1 / \theta} \lambda_{2}\right) .
\end{gathered}
$$

Then, Property 2 implies that

$$
\min \left[\left(w_{1}\right)^{1 / \theta} a_{1}(x)^{1 / \theta},\left(w_{2} \tau_{2}\right)^{1 / \theta} a_{2}(x)^{1 / \theta}\right] \sim \exp \left(\left(w_{1}\right)^{-1 / \theta} \lambda_{1}+\left(w_{2} \tau_{2}\right)^{-1 / \theta} \lambda_{2}\right) .
$$

Finally, appealing to Property 1 again,

$$
p_{1}(x)^{1 / \theta} \sim \exp \left(\left(w_{1}\right)^{-1 / \theta} \lambda_{1}+\left(w_{2} \tau_{2}\right)^{-1 / \theta} \lambda_{2}\right) .
$$

Now let $\mu_{1}=\left(w_{1}\right)^{-1 / \theta} \lambda_{1}+\left(w_{2} \tau_{2}\right)^{-1 / \theta} \lambda_{2}$. Then 


$$
P_{1}^{1-\eta}=\mu_{1} \int t^{\theta(1-\eta)} \exp \left(-\mu_{1} t\right) d t
$$

Apply a change of variables so that $\omega_{1}=\mu_{1} t$ and obtain

$$
P_{1}^{1-\eta}=\left(\mu_{1}\right)^{\theta(\eta-1)} \int \omega_{1}^{\theta(1-\eta)} \exp \left(-\omega_{1}\right) d \omega_{1} .
$$

Let $\gamma=\Gamma(1+\theta(1-\eta))^{1 /(1-\eta)}$, where $\Gamma(\cdot)$ is the gamma function. Therefore,

$$
\begin{aligned}
P_{1} & =\gamma\left(\mu_{1}\right)^{-\theta} \\
& =\gamma\left[\left(w_{1}\right)^{-1 / \theta} \lambda_{1}+\left(w_{2} \tau_{2}\right)^{-1 / \theta} \lambda_{2}\right]^{-\theta} \\
& =\gamma w_{1} \lambda_{1}^{-\theta}\left[1+\left(\frac{w_{2}}{w_{1}}\right)^{-1 / \theta} \tau_{2}^{-1 / \theta}\left(\frac{\lambda_{2}}{\lambda_{1}}\right)\right]^{-\theta} .
\end{aligned}
$$

Using analogous logic, the price index in country 2 can be expressed as

$$
\begin{aligned}
P_{2} & =\gamma\left(\mu_{2}\right)^{-\theta} \\
& =\gamma\left[\left(w_{1} \tau_{1}\right)^{-1 / \theta} \lambda_{1}+\left(w_{2}\right)^{-1 / \theta} \lambda_{2}\right]^{-\theta} \\
& =\gamma w_{1} \lambda_{1}^{-\theta}\left[\tau_{1}^{-1 / \theta}+\left(\frac{w_{2}}{w_{1}}\right)^{-1 / \theta}\left(\frac{\lambda_{2}}{\lambda_{1}}\right)\right]^{-\theta} .
\end{aligned}
$$

Using the expressions for price indexes, the relative price between the two countries is

$$
\frac{P_{1}}{P_{2}}=\left[\frac{1+\left(\frac{w_{2}}{w_{1}}\right)^{-1 / \theta} \tau_{2}^{-1 / \theta}\left(\frac{\lambda_{2}}{\lambda_{1}}\right)}{\tau_{1}^{-1 / \theta}+\left(\frac{w_{2}}{w_{1}}\right)^{-1 / \theta}\left(\frac{\lambda_{2}}{\lambda_{1}}\right)}\right]^{-\theta}
$$

Trade Flows. We now derive the trade shares $\pi_{i j}$, the fraction of country $i$ 's total spending on goods that were obtained from country $j$. As in the Eaton and Kortum (2002) setup, $\pi_{i j}$ is also the probability that country $j$ is the least-cost supplier of an arbitrary good $x$. For instance,

$$
\pi_{12}=\operatorname{Pr}\left\{p_{12}(x) \leq p_{11}(x)\right\} .
$$

Cost minimization by producers of good $x$ in country $i$ implies that the cost of each unit of labor is equal to the wage rate $w_{i}$. Perfect competition implies that the price in country 1 of intermediate good $x$, when purchased from country 2, equals the unit cost in country 2 times the trade barrier. Hence, 


$$
\begin{aligned}
\pi_{12} & =\operatorname{Pr}\left\{w_{2} \tau_{2} a_{2}(x) \leq w_{1} a_{1}(x)\right\} \\
& =\operatorname{Pr}\left\{\left(w_{2} \tau_{2} a_{2}(x)\right)^{1 / \theta} \leq\left(w_{1} a_{1}(x)\right)^{1 / \theta}\right\} \\
& =\frac{\left(w_{2} \tau_{2}\right)^{-1 / \theta} \lambda_{2}}{\left(w_{1}\right)^{-1 / \theta} \lambda_{1}+\left(w_{2} \tau_{2}\right)^{-1 / \theta} \lambda_{1}}(\text { by Properties 1 and } 3) \\
& =\frac{1}{1+\left(\frac{w_{1}}{w_{2}}\right)^{-1 / \theta} \tau_{2}^{1 / \theta}\left(\frac{\lambda_{1}}{\lambda_{2}}\right)} .
\end{aligned}
$$

Similarly,

$$
\pi_{21}=\frac{1}{1+\left(\frac{w_{2}}{w_{1}}\right)^{-1 / \theta} \tau_{1}^{1 / \theta}\left(\frac{\lambda_{2}}{\lambda_{1}}\right)}
$$

Testable Implication. From the expression for $\pi_{21}$, we can infer $\pi_{22}$ as

$$
\begin{aligned}
\pi_{22}= & 1-\pi_{21} \\
= & \frac{\left(\frac{w_{2}}{w_{1}}\right)^{-1 / \theta} \tau_{1}^{1 / \theta}\left(\frac{\lambda_{2}}{\lambda_{1}}\right)}{1+\left(\frac{w_{2}}{w_{1}}\right)^{-1 / \theta} \tau_{1}^{1 / \theta}\left(\frac{\lambda_{2}}{\lambda_{1}}\right)} .
\end{aligned}
$$

Hence,

$$
\frac{\pi_{12}}{\pi_{22}}=\frac{\tau_{1}^{-1 / \theta} \tau_{2}^{-1 / \theta}+\left(\frac{w_{2}}{w_{1}}\right)^{-1 / \theta} \tau_{2}^{-1 / \theta}\left(\frac{\lambda_{2}}{\lambda_{1}}\right)}{1+\left(\frac{w_{2}}{w_{1}}\right)^{-1 / \theta} \tau_{2}^{-1 / \theta}\left(\frac{\lambda_{2}}{\lambda_{1}}\right)}
$$

From expression (B1) for the relative price, it is easy to see that

$$
\frac{\pi_{12}}{\pi_{22}}=\left(\frac{P_{2}}{P_{1}}\right)^{-1 / \theta} \tau_{2}^{-1 / \theta}
$$

To deliver price equalization in our model, $\tau$ is negatively correlated with $\lambda$. Thus, for an importing country $i$, we can compute the ratio $\left(\frac{\pi_{i j}}{\pi_{j j}}\right)$ for all countries $j$ that export to country $i$ and test whether this ratio is positively correlated with $\lambda_{j}$. 
Mutreja, Ravikumar, Riezman, Sposi

\section{NOTE}

1 In equilibrium, each country will produce only a subset of the goods and import the rest. Therefore, average measured productivity will depend on the range of goods produced and will be endogenous.

\section{REFERENCES}

Anderson, James and van Wincoop, Eric. "Gravity with Gravitas: A Solution to the Border Puzzle." American Economic Review, March 2003, 93(1), pp. 170-92.

Armenter, Roc and Lahiri, Amartya. "Accounting for Development Through Investment Prices." Journal of Monetary Economics, October 2012, 59(6), pp. 550-64.

Dornbusch, Rudiger; Fischer, Stanley and Samuelson, Paul A. “Comparative Advantage, Trade, and Payments in a Ricardian Model with a Continuum of Goods." American Economic Review, December 1977, 67(5), pp. 823-39.

Eaton, Jonathan and Kortum, Samuel. "Technology, Geography, and Trade." Econometrica, September 2002, 70(5), pp. 1741-79.

Hsieh, Chang-Tai and Klenow, Peter J. "Relative Prices and Relative Prosperity." American Economic Review, June 2007, 97(3), pp. 562-85.

McCallum, John. "National Borders Matter: Canada-U.S. Regional Trade Patterns." American Economic Review, June 1995, 85(3), pp. 615-23.

Mutreja, Piyusha; Ravikumar, B.; Riezman, Raymond and Sposi, Michael J. “Price Equalization, Trade Flows, and Barriers to Trade." European Economic Review, August 2014, 70, pp. 383-98.

Taylor, Alan M. and Taylor, Mark P. “The Purchasing Power Parity Debate." Journal of Economic Perspectives, Fall 2004, 18(4), pp. 135-58. 
